\title{
Immediate function with four zygomatic implants in patients with extreme maxillary atrophy - Case series
}

\section{Duarte $F^{1}$, Ramos $C^{1}$, Silva $J N^{2}$}

\section{Affiliations:}

1. CEO and Clinical Director of Clitrofa Trofa - Portugal

2. Instituto Superior de Saúde ISAVE, Portugal

\section{Corresponding Author:}

Fernando Duarte

E-mail:fduarte@clitrofa.com

\section{ABSTRACT}

Purpose: Zygomatic implants have been in use since the 1990's for the treatment of patients with severely resorbed maxillae. Eliminating grafting combined with immediate function increases patient acceptance.

The purpose of this study was to evaluate a protocol for immediate function with fixed prostheses for patients with extreme maxillary atrophy, treated with four zygomatic implants (S.I.N.-Implant System, São Paulo, Brazil).

Case series: This retrospective clinical study included 10 patients with 40 immediately loaded zygomatic implants with fixed provisional acrylic prosthesis attached 5 to 6 hours after surgery. The patients' follow-up was from 12 to 60 months. Two zygomatic implants failed (implant survival rate 95\%). There were no complications such as sinusitis, hygiene maintenance or speech impairment.

The results support the hypothesis that immediate function with four zygomatic implants is a viable concept. The clinical success for these patients was enhanced by the shorter time span of the treatment process and the immediate rehabilitation in a comfortable manner as compared to grafting based procedures.

Conclusion: The high survival rate, the increase of patient's demand in immediate functional ability and the less morbidity following the surgical procedure renders this immediate function zygomatic procedure a viable treatment option of the resorbed fully edentulous maxillae.

\section{KEYWORDS}

Zygomatic implant, edentulous maxilla, atrophic maxilla, fixed maxillary prosthesis, immediate-function, immediate loading 


\section{INTRODUCTION}

Zygomatic implants have shown good clinical success rates in clinical studies, most often close to $100 \%$ success with followup periods of up to 5 years. ${ }^{16,17,18,19}$ Sinuscopy performed in patients with zygomatic implants showed no signs of infection or inflammation in the surrounding mucosa. ${ }^{20}$ The original concept featured a single implant in the zygoma bilaterally, combined with 2 to 4 conventional implants in the anterior maxilla. Although the method has proved to be predictable, bone grafting to the region below the nasal aperture is sometimes required prior to implant placement. $11,22,23,24,25$ In an effort to provide a graft-free procedure for patients with atrophic maxillae and very severe bone resorption in the anterior maxilla, a modified technique utilizing multiple zygomatic implants anchored in the zygoma bone is presented.

Immediate function, a well documented concept, $26,27,28,29$ where implants are immediately loaded after insertion has shown high success rates, provided high primary stability. ${ }^{30}$ Histological analysis of the zygoma bone shows regular trabeculae and compact bone with an osseous density of up to $98 \%{ }^{31}$ Due to this high bone density ${ }^{31}$ and the high documented clinical success rates for zygomatic implants ${ }^{16-19}$ it can be anticipated that this bone is suitable for immediate function.

The objective of the current study was to test the hypothesis that the immediate function protocol using four zygomatic implants in patients with extreme maxillary atrophy can be considered as a rehabilitation alternative.

\section{MATERIALS AND METHODS}

The study was based on 10 patients treated at Clitrofa - Centro Médico, Dentário e Cirúrgico Lda. (Trofa - Portugal), by one and the same team, between January 2015 and January 2019, provided they met the inclusion criteria and gave their written consent to the procedure. The patients had four zygomatic implants (S.I.N.-Implant System, São Paulo, Brazil) placed bilaterally, all with straight abutments (S.I.N.-Implant System, São Paulo, Brazil). The patients were 7 women and 3 men, the average age for the women being 58,57 $\pm 12,67$ years and for the men $69,67 \pm 2,31$ years. All the patients were non-smokers. Details of implant and abutment dimension per position and types of opposing jaws are shown in Table 1.

\section{Inclusion criteria}

The inclusion criteria for the treatment were: i) need for complete rehabilitation of the edentulous maxilla; ii) no possibility for insertion of 5-6 standard implants in the anterior region of the maxilla; iii) a posterior bone height of less than $5 \mathrm{~mm}$; iv) no sinusitis, polyps or any sinuses pathology; and v) psychological motivation to be treated.

\section{Surgical and prosthetic procedure}

The pre-surgical radiographic evaluation included panoramic radiographs and CT scans which has been used previously $2,9,10$ to identify the anatomic structures and detect any presence of pathology at the 3 levels to investigate: the maxilla, the sinus and the zygoma bone. Preoperative considerations should also involve shape of the face, degree of resorption, maxillomandibular jaw relationship and patient expectations. A narrow face will be unfavourable as far as intraoperative access and implant inclination are concerned. An edentulous mandible will facilitate access.

A palatal $45^{\circ}$ incision along the entire maxillary crest, combined with a full thickness flap from maxillary crest to zygoma buttress and the suborbital nerve identification are the first steps to this surgery. ${ }^{7,8}$ In order to determine the orientation of the zygomatic implant and to reflect the schneiderian membrane, a window was made by cutting at the upper limit between the zygoma bone and the sinus using a piezoelectric device. This window was also helpful during the surgical procedure for cooling the drills to avoid overheating., 2,4,27 In patients with existing implantsupported prostheses in the mandible, the prosthesis should be removed prior to the surgery.

Different drills were used with increasing diameters, ending with the insertion at low speed of the self-tapping zygomatic implant. The implant length was chosen by means of a gauge and can go from $32.5 \mathrm{~mm}$ to $62.5 \mathrm{~mm}$.

The most posterior implant is placed first, the palatal entrance is made in the second molar region, with the implant running slightly posterior to the buttress and perforating the zygoma bone from the medial side. The entrance in the zygoma should be low and posterior, care must be taken to retract the soft tissue. It is important to use sharp twist drills; otherwise the drill will bend and slide along the medial side of the zygoma, or it may cause a fracture of the arch.

The second implant is placed in the premolar region, running along the infrazygomatic crest inside the sinus and perforating the middle aspect of the zygoma bone. ${ }^{11,12,13,14}$

Ideally, each implant should be supported by surrounding bone, at both the neck and the apex. Often, the crestal bone is very thin, and thus it is easy to create an entrance hole that is wider than the implant. In patients with very severe resorption, the entrance is sometimes located in compact palatal bone. It is

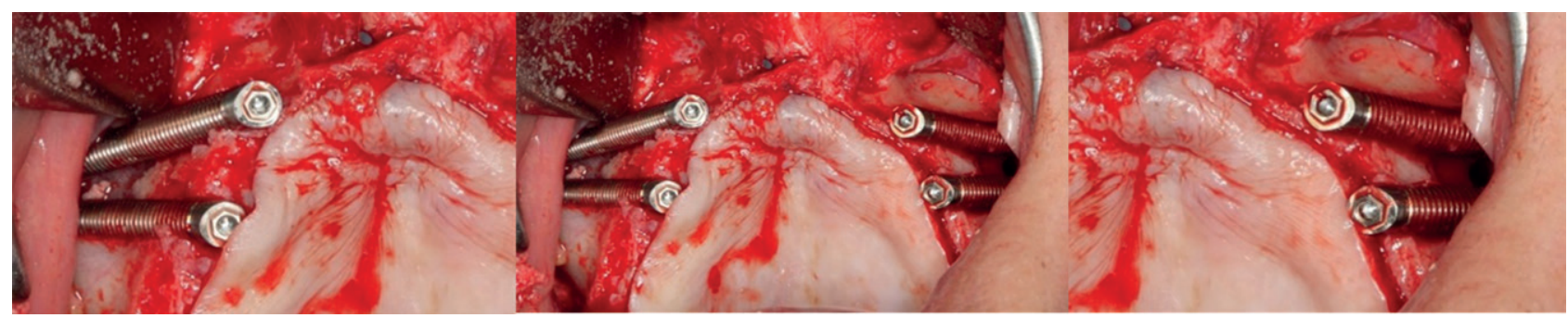

Figure 1. Intraoperative image showing the zygomatic implants position

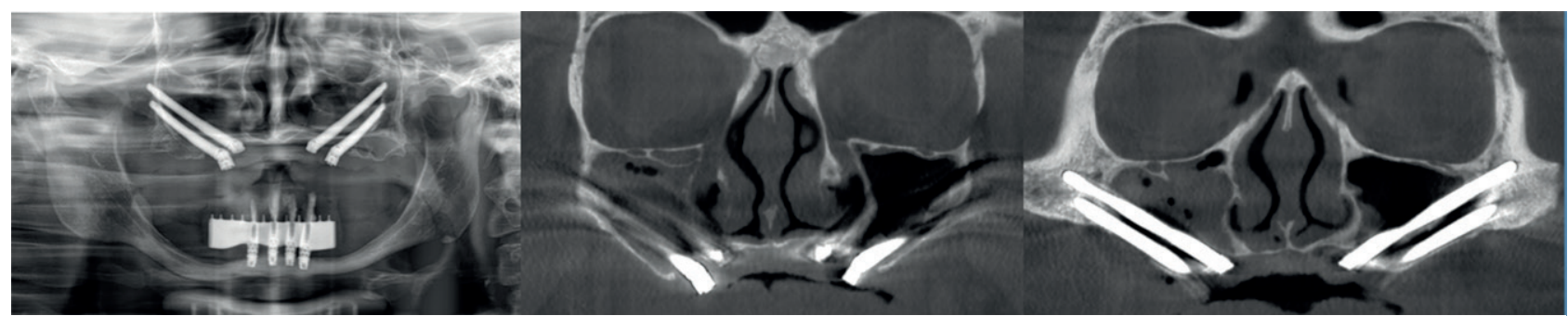

Figure 2. Post-operative imagiological protocol included panoramic radiographs and CT scans 
then important that the palatal hole and the hole in the zygoma have exactly the same direction to avoid tension and difficulties during implant placement.

After insertion of the implants, the abutments were placed on the top of the zygomatic implant, the soft tissue closed and an immediate (5-6 hours after) provisional acrylic prosthesis reinforced by a metal strip, was provided for the patient. Final prostheses were placed after 5-6 months. ${ }^{32,33,34}$

\section{Survival criteria}

An implant was classified as surviving if it fulfilled its purported function and was stable when tested individually after the removal of the prosthesis. Lack of gross mobility as well as the absence of pain upon percussion along with no sign of periimplant pathology further determined the survivability of the implants.

\section{Follow-up}

The patients were followed-up and the implants were checked for survival after 3 and 6 months and then once a year. It was not possible to judge the marginal bone change at the zygomatic implants as their placement orients the implant platform slightly palatal to the crest, superimposing the marginal bone over the implant. Orthopantomograms were done on all the patients after provisional and definitive prosthesis insertion and a tomography at 12 months follow-up. All patients were followed-up according to plan and no dropout occurred.

\section{RESULTS}

Follow-up of the patients from 12 to 60 months revealed no clinical symptoms but two of the 40 zygomatic implants failed, which means a success rate of 95\% (Table 2). The prosthesis survival was $100 \%$.

During surgery, the sinus membrane was perforated in all the cases; however, there were no important postoperative complication. In all cases substantial benefit in terms of oral function was obtained, and all patients reported improvement in self-esteem and social relations.

\section{Complications}

Two complications were detected in 2 patients who lost one implant each; in both cases the implant lost was the first quadrant anterior zygoma.

A third complication was detected in 1 patient who presented a severe infection of the maxillary sinus, which was successfully treated with antibiotics.

\section{TABLES}

Table 1. Distribution of the Zygomatic Implants in Immediate Function

\begin{tabular}{|c|c|c|c|c|c|c|c|}
\hline \multirow{2}{*}{ Case } & \multirow{2}{*}{ Age } & \multirow{2}{*}{ Sex } & \multicolumn{4}{|c|}{$\begin{array}{l}\text { Zygomatic Implant } \\
\text { Length }(\mathrm{mm})\end{array}$} & \multirow{2}{*}{ Antagonist occlusion } \\
\hline & & & 1stQAZ & 1stQPZ & 2ndQAZ & 2ndQPZ & \\
\hline 1 & \multirow{2}{*}{68} & \multirow{2}{*}{$\mathrm{F}$} & $42.5 \mathrm{~mm}$ & $45 \mathrm{~mm}$ & $42.5 \mathrm{~mm}$ & $45 \mathrm{~mm}$ & \multirow{2}{*}{ Overdenture } \\
\hline Abutment Type & & & $3 \mathrm{~mm}$ & $3 \mathrm{~mm}$ & $3 \mathrm{~mm}$ & $3 \mathrm{~mm}$ & \\
\hline 2 & \multirow{2}{*}{67} & \multirow{2}{*}{ M } & $45 \mathrm{~mm}$ & $45 \mathrm{~mm}$ & $45 \mathrm{~mm}$ & $45 \mathrm{~mm}$ & \multirow{2}{*}{ Acrylic prosthesis } \\
\hline Abutment Type & & & $3 \mathrm{~mm}$ & $3 \mathrm{~mm}$ & $3 \mathrm{~mm}$ & $3 \mathrm{~mm}$ & \\
\hline 3 & \multirow{2}{*}{71} & \multirow{2}{*}{ M } & $45 \mathrm{~mm}$ & $47.5 \mathrm{~mm}$ & $42.5 \mathrm{~mm}$ & $47.5 \mathrm{~mm}$ & \multirow{2}{*}{ Natural Teeth } \\
\hline Abutment Type & & & $3 \mathrm{~mm}$ & $3 \mathrm{~mm}$ & $3 \mathrm{~mm}$ & $3 \mathrm{~mm}$ & \\
\hline 4 & \multirow{2}{*}{70} & \multirow{2}{*}{$\mathrm{F}$} & $42.5 \mathrm{~mm}$ & $50 \mathrm{~mm}$ & $45 \mathrm{~mm}$ & $50 \mathrm{~mm}$ & \multirow{2}{*}{ Natural Teeth } \\
\hline Abutment Type & & & $3 \mathrm{~mm}$ & $3 \mathrm{~mm}$ & $3 \mathrm{~mm}$ & $3 \mathrm{~mm}$ & \\
\hline 5 & \multirow{2}{*}{73} & \multirow{2}{*}{$\mathrm{F}$} & $32.5 \mathrm{~mm}$ & $35 \mathrm{~mm}$ & $32.5 \mathrm{~mm}$ & $35 \mathrm{~mm}$ & \multirow{2}{*}{$\begin{array}{l}\text { Total Implant-supported } \\
\text { Rehab. }\end{array}$} \\
\hline Abutment Type & & & $3 \mathrm{~mm}$ & $3 \mathrm{~mm}$ & $3 \mathrm{~mm}$ & $3 \mathrm{~mm}$ & \\
\hline 6 & \multirow{2}{*}{54} & \multirow{2}{*}{$\mathrm{F}$} & $32.5 \mathrm{~mm}$ & $32.5 \mathrm{~mm}$ & $32.5 \mathrm{~mm}$ & $32.5 \mathrm{~mm}$ & \multirow{2}{*}{$\begin{array}{l}\text { Total Implant-supported } \\
\text { Rehab. }\end{array}$} \\
\hline Abutment Type & & & $3 \mathrm{~mm}$ & $3 \mathrm{~mm}$ & $3 \mathrm{~mm}$ & $3 \mathrm{~mm}$ & \\
\hline 7 & \multirow{2}{*}{58} & \multirow{2}{*}{$\mathrm{F}$} & $35 \mathrm{~mm}$ & $40 \mathrm{~mm}$ & $32.5 \mathrm{~mm}$ & $35 \mathrm{~mm}$ & \multirow{2}{*}{$\begin{array}{l}\text { Total Implant-supported } \\
\text { Rehab. }\end{array}$} \\
\hline Abutment Type & & & $3 \mathrm{~mm}$ & $3 \mathrm{~mm}$ & $3 \mathrm{~mm}$ & $3 \mathrm{~mm}$ & \\
\hline 8 & \multirow{2}{*}{49} & \multirow{2}{*}{ F } & $40 \mathrm{~mm}$ & $45 \mathrm{~mm}$ & $37.5 \mathrm{~mm}$ & $40 \mathrm{~mm}$ & \multirow{2}{*}{ Overdenture } \\
\hline Abutment Type & & & $3 \mathrm{~mm}$ & $3 \mathrm{~mm}$ & $3 \mathrm{~mm}$ & $3 \mathrm{~mm}$ & \\
\hline 9 & \multirow{2}{*}{71} & \multirow{2}{*}{ M } & $45 \mathrm{~mm}$ & $47.5 \mathrm{~mm}$ & $42.5 \mathrm{~mm}$ & $47.5 \mathrm{~mm}$ & \multirow{2}{*}{ Natural Teeth } \\
\hline Abutment Type & & & $3 \mathrm{~mm}$ & $3 \mathrm{~mm}$ & $3 \mathrm{~mm}$ & $3 \mathrm{~mm}$ & \\
\hline 10 & \multirow{2}{*}{38} & \multirow{2}{*}{$\mathrm{F}$} & $37.5 \mathrm{~mm}$ & $42 \mathrm{~mm}$ & $45 \mathrm{~mm}$ & $50 \mathrm{~mm}$ & Total Implant-supported \\
\hline Abutment Type & & & $3 \mathrm{~mm}$ & $3 \mathrm{~mm}$ & $3 \mathrm{~mm}$ & $3 \mathrm{~mm}$ & Rehab. \\
\hline
\end{tabular}


Table 2. Life table analysis Zygomatic Implants

\begin{tabular}{|l|l|l|l|l|l|}
\hline Number of implants & & & & & \\
\hline Duration & Total & Failed & Withdrawn & Not yet due & CSR \\
\hline Placement- 6mo & 0 & 0 & 0 & 0 & $100,0 \%$ \\
\hline 6mo- 1 yr & 0 & 0 & 0 & 0 & $100,0 \%$ \\
\hline $\mathbf{1 - 2}$ yrs & 18 & 1 & 0 & 0 & $100,0 \%$ \\
\hline 2- 3 yrs & 16 & 0 & 0 & 0 & $100,0 \%$ \\
\hline 3- $\mathbf{y r s}$ & 16 & 1 & 0 & 0 & $100,0 \%$ \\
\hline
\end{tabular}

CSR= Cumulative survival rate

\section{DISCUSSION}

The result, 95\% zygomatic implant survival rates and 100\% prosthesis survival rate, supports the hypothesis that immediate function with four zygomatic implants is a viable concept. The high survival rate of the zygomatic implants mimics that of the 2-stage protocol ${ }^{15,16}$ and it can be hypothesized that the dense bone structure of the zygoma bone is a contributing factor for this good outcome.

The clinical success for these patients was enhanced by the shorter time span of the treatment process. This technique allows the reduction in the total treatment time by eliminating the months usually required for bone grafts to mature before performing implants and eliminates the necessity of additional healing time required for implants. ${ }^{6,23,35,36} \mathrm{As}$ a consequence, the patients get immediate rehabilitation in a comfortable manner as compared to the grafting based procedures.

Furthermore, there are other benefits for patients subjected to this graftless treatment, such as improvement in self-esteem and social relationships which has been observed in the current study and by others. ${ }^{37}$

\section{CONCLUSION}

The presence of sufficient bone volumes is one of the most important variables for successful oral osteointegration of implants ${ }^{1}$, wherefore restoration of atrophied edentulous maxilla poses a great dilemma for the surgeon and restorative dentist. Sinus bone grafting to build new bone for implant anchorage in atrophied jaws entail multiple surgical interventions, varying success rates of the implants, potential for donor site morbidity as well as increased surgical fees. ${ }^{2,3}$

Zygomatic implants with this technique may allow the surgical rehabilitation of patients presenting with severe maxillary resorption, providing a valid alternative with excellent support to dental rehabilitation either functionally either aesthetically.

\section{CONFLICT OF INTEREST}

The authors declares that there is no conflict of interest regarding the publication of this article. 


\section{REFERENCES}

1. Higuchi KW. The zygomaticus fixture: an alternative approach for implant anchorage in the posterior maxilla. Ann R Australas Coll Dent Surg 2000;15:28-33.

2. Malevez C, Daelemans P, Adriaenssens P, Durdu F. Use of zygomatic implants to deal with resorbed posterior maxillae. Periodontol 2000 2003;33:82-9.

3. Jensen O, Rangert B, Aparicio C, Malevez C, Bedrossian E, Renouard F, Maló P, Calandiello R. The Sinus Bone Graft. Quintessence Publishing Co, Inc, 2006.

4. Inroads in implantology: managing the severely resorbed maxillary alveolus. Sadj 2000;55:120-1.

5. Stella JP, Warner MR. Sinus slot technique for simplification and improved orientation of zygomaticus dental implants: a technical note. Int J Oral Maxillofac Implants 2000;15:889-93.

6. Bedrossian E, Stumpel LJ, 3rd. Immediate stabilization at stage Il of zygomatic implants: rationale and technique. J Prosthet Dent 2001;86:10-4

7. Boyes-Varley JG, Howes DG, Lownie JF, Blackbeard GA. Surgical modifications to the Branemark zygomaticus protocol in the treatment of the severely resorbed maxilla: a clinical report. Int J Oral Maxillofac Implants 2003;18:232-7.

8. Boyes-Varley JG, Howes DG, Lownie JF. The zygomaticus implant protocol in the treatment of the severely resorbed maxilla. Sadj 2003;58:106-9, 113-4.

9. Vrielinck L, Politis C, Schepers S, Pauwels M, Naert I. Image-based planning and clinical validation of zygoma and pterygoid implant placement in patients with severe bone atrophy using customized drill guides. Preliminary results from a prospective clinical follow-up study. Int J Oral Maxillofac Surg 2003;32:7-14.

10. Van Steenberghe D, Malevez C, Van Cleynenbreugel J, Serhal CB, Dhoore E, Schutyser F, Suetens P, Jacobs R. Accuracy of drilling guides for transfer from threedimensional CT-based planning to placement of zygoma implants in human cadavers. Clin Oral Implants Res 2003;14:131-6.

11. Nkenke E, Hahn M, Lell M, Wiltfang J, Schultze-Mosgau S, Stech B, Radespiel-Troger M, Neukam FW. Anatomic site evaluation of the zygomatic bone for dental implant placement. Clin Oral Implants Res 2003;14:72-9.

12. Abarca M, Nejadnik S, Daelemans P, Malevez C. Reconance frequency measurements of zygomatic implant stability. Preliminary results. Clin Oral Implants Res 2003; 14:xxix.

13. Rigolizzo MB, Camilli JA, Francischone CE, Padovani CR, Branemark PI. Zygomatic bone: anatomic bases for osseointegrated implant anchorage. Int J Oral Maxillofac Implants 2005;20:441-7.

14. Kato Y, Kizu Y, Tonogi M, Ide Y, Yamane GY. Internal structure of zygomatic bone related to zygomatic fixture. J Oral Maxillofac Surg 2005;63:1325-9.

15. Bedrossian E, Stumpel L, 3rd, Beckely ML, Indresano T. The zygomatic implant: preliminary data on treatment of severely resorbed maxillae. A clinical report. Int J Oral Maxillofac Implants 2002;17:861-5.

16. Malevez C, Abarca M, Durdu F, Daelemans P. Clinical outcome of 103 consecutive zygomatic implants: a 6-48 months follow-up study. Clin Oral Implants Res 2004;15:18-22.

17. Patel RR, Brook MI, Wragg PF. Zygoma implants or sinus augmentation and conventional implants? Clin Oral Implants Res 2003;14:xxxix.

18. Stevenson AR, Austin BW. Zygomatic fixtures--the Sydney experience. Ann R Australas Coll Dent Surg 2000;15:337-9.

19. Branemark PI, Grondahl K, Ohrnell LO, Nilsson P, Petruson B, Svensson B, Engstrand P, Nannmark U. Zygoma fixture in the management of advanced atrophy of the maxilla: technique and long-term results. Scand J Plast Reconstr Surg Hand Surg 2004;38:70-85.

20. Hirsch JM, Ohrnell LO, Henry PJ, Andreasson L, Branemark PI, Chiapasco M, Gynther G, Finne K, Higuchi KW, Isaksson S, Kahnberg KE, Malevez C, Neukam FW, Sevetz E, Urgell JP, Widmark G, Bolind P. A clinical evaluation of the Zygoma fixture: one year of follow-up at 16 clinics. J Oral Maxillofac Surg 2004;62:22-9.

21. Weischer T, Schettler D, Mohr C. Titanium implants in the zygoma as retaining elements after hemimaxillectomy. Int J Oral Maxillofac Implants 1997;12:211-4.

22. Tamura H, Sasaki K, Watahiki R. Primary insertion of implants in the zygomatic bone following subtotal maxillectomy. Bull Tokyo Dent Coll 2000;41:21-4.

23. Balshi TJ, Wolfinger GJ. Treatment of congenital ectodermal dysplasia with zygomatic implants: a case report. Int J Oral Maxillofac Implants 2002;17:277-81.

24. Penarrocha-Diago M, Uribe-Origone R, Rambla-Ferrer J, Guarinos-Carbo J. Fixed rehabilitation of a patient with hypohidrotic ectodermal dysplasia using zygomatic implants. Oral Surg Oral Med Oral Pathol Oral Radiol Endod 2004;98:161-5.

25. Penarrocha-Diago M, Uribe-Origone R, Guarinos-Carbo J. Implant-supported rehabilitation of the severely atrophic maxilla: a clinical report. J Prosthodont 2004;13:187-91.

26. Balshi TJ, Wolfinger GJ. Teeth in a day for the maxilla and mandible: case report. Clin Implant Dent Relat Res 2003;5:11-6.

27. Balshi TJ, Wolfinger GJ. Immediate loading of dental implants in the edentulous maxilla: case study of a unique protocol. Int J Periodontics Restorative Dent 2003;23:37-45.

28. Nakai H, Okazaki Y, Ueda M. Clinical application of zygomatic implants for rehabilitation of the severely resorbed maxilla: a clinical report. Int J Oral Maxillofac Implants 2003;18:566-70

29. Salinas TJ. Extended-length implants for reconstruction of the edentulous-maxilla. Pract Proced Aesthet Dent 2001;13:608

30. Balshi SF, Wolfinger GJ, Balshi TJ. Analysis of 164 titanium oxide-surface implants in completely edentulous arches for fixed prosthesis anchorage using the pterygomaxillary region. Int J Oral Maxillofac Implants 2005;20:946-52.

31. Gosain AK, Song L, Capel CC, Corrao MA, Lim TH. Biomechanical and histologic alteration of facial recipient bone after reconstruction with autogenous bone grafts and alloplastic implants: a 1-year study. Plast Reconstr Surg 1998;101:1561-71.

32. Al-Nawas B, Wegener J, Bender C, Wagner W. Critical soft tissue parameters of the zygomatic implant. J Clin Periodontol 2004;31:497-500.

33. Landes CA. Zygoma implant-supported midfacial prosthetic rehabilitation: a 4-year follow-up study including assessment of quality of life. Clin Oral Implants Res 2005; 16:313-25.

34. Bedrossian E, Rangert B, Stumpel L, Indersano T. Immediate function with the Zygoma implant - A graft-less solution for the patient with mild to advanced atrophy of the maxilla. Int J Oral Maxillofac Implants 2006; (accepted for publication).

35. Ferrara ED, Stella JP. Restoration of the edentulous maxilla: the case for the zygomatic implants. J Oral Maxillofac Surg 2004;62:1418-22.

36. Pham AV, Abarca M, De Mey A, Malevez C. Rehabilitation of a patient with cleft lip and palate with an extremely edentulous atrophied posterior maxilla using zygomatic implants: case report. Cleft Palate Craniofac J 2004;41:571-4.

37. Penarrocha M, Uribe R, Garcia B, Marti E. Zygomatic implants using the sinus slot technique: clinical report of a patient series. Int J Oral Maxillofac Implants 2005;20:788-92 